\title{
Does predicted age at peak height velocity explain physical performance in U13-15 basketball female players?
}

\author{
Karol Gryko ${ }^{1 *} \mathbb{D}$, Jakub Grzegorz Adamczyk ${ }^{2} \mathbb{D}$, Anna Kopiczko ${ }^{3}$, Jorge Lorenzo Calvo ${ }^{4}$, \\ Alberto Lorenzo Calvo ${ }^{4}$ and Kazimierz Mikołajec ${ }^{5}$ (D)
}

\begin{abstract}
Background: The aims of the study were (1) to identify the physical fitness and basic anthropometric characteristics of Polish female basketball players aged 13-15 years, (2) to show the effect of maturity timing on the performance in motor tests and basic body composition parameters, (3) to identify the index that contributes most to the prediction of performance in the tests of speed, jumping ability, agility, and endurance.
\end{abstract}

Methods: The sample included 904 female Polish players (U13-15). In part 1, maturity timing category distribution were examined within across age-groups. Maturity timing was followed by grouping with respect to years before or after the observed peak high velocity (PHV): PHVO ( -0.50 to 0.49), PHV1 (0.50 to 1.49), PHV2 (1.50 to 2.49) and PHV3 (2.50 to 3.49). In part 2, the relationship between the anthropometric variables, physical fitness performance was assessed based on maturity timing categories (ANCOVA analysis). In part 3, backward stepwise multiple regression analyse quantified the relationship between maturity timing (group of PHV) and physical performance.

Results: ANCOVA results (age, body height, and body mass as covariates) showed in the U13 female basketball players significantly higher sprinting $(20 \mathrm{~m})$, jumping ability and endurance tests results of the PHV1 group. Better results was observed in U14 female players in PHV1 compared to PHV2 and PHV3 in $20 \mathrm{~m}$ and jumping tests but opposite trend was observed for $5 \mathrm{~m}$ sprint and endurance test (distance covered and $\mathrm{VO}_{\text {max }}$ ). U15 basketball players from the PHV3 group were characterized by better results of jumping abilities, endurance, $10 \mathrm{~m}$ and $20 \mathrm{~m}$ sprint and agility (total, $\left.\mathrm{S}_{4}\right)$ tests. Maturity timing $(10 \mathrm{~m})$, chronological age $\left(5 \mathrm{~m}, 20 \mathrm{~m}\right.$, agility, $\mathrm{SVJ}, \mathrm{VJ}$, and $\mathrm{VO}_{2 \mathrm{max}}$ tests), body height $(10 \mathrm{~m})$, body mass $\left(10 \mathrm{~m}, 20 \mathrm{~m}, \mathrm{VJ}, \mathrm{VO}_{2 \max }\right)$, and the interaction between body mass and height (SVJ) were significant (adjusted $R^{2}=0.02-0.10 ; p<0.001$ ) predictors of motor skills.

Conclusion: Trainng content of female basketball players aged 13-15 years old should be adjusted to biological requirements especially in jumping, endurance and $20 \mathrm{~m}$ sprint test. The time from peak height velocity (PHV) was a significant predictor only in the $10 \mathrm{~m}$ sprint test.

Keywords: Maturity timing, Adolescent development, Athletes, Physical fitness, Aptitude

*Correspondence: karol.gryko@awf.edu.pl

1 Department of Sport Games, Józef Piłsudski University of Physical Education in Warsaw, Marymoncka 34, 00-968 Warsaw, Poland

Full list of author information is available at the end of the article

\section{Background}

Basketball is a sport characterized by intermittent highintensity exercise [1, 2], whereas optimal performance in basketball is achieved through a complex combination of technical and tactical skills and high physical fitness [3]. Athletes who train basketball, the need to analyze many original author(s) and the source, provide a link to the Creative Commons licence, and indicate if changes were made. The images or other third party material in this article are included in the article's Creative Commons licence, unless indicated otherwise in a credit line to the material. If material is not included in the article's Creative Commons licence and your intended use is not permitted by statutory regulation or exceeds the permitted use, you will need to obtain permission directly from the copyright holder. To view a copy of this licence, visit http://creativecommons.org/licenses/by/4.0/. The Creative Commons Public Domain Dedication waiver (http://creativeco mmons.org/publicdomain/zero/1.0/) applies to the data made available in this article, unless otherwise stated in a credit line to the data. 
variables such as physical and physiological attributes (body height, body mass, somatotype, body proportions, aerobic profile, strength, anaerobic power, agility, and speed) is emphasized [4]. Talent identification requires multifactorial analyses of several biological [5-7], functional, behavioural and perceptual variables [8] and those related to the training process [9]. Studies indicate the validity and necessity of taking into account chronological age and predicted age at peak height velocity (APHV) of basketball players to optimize the process of identifying gifted individuals [10].

Maturity status (early, on time, late, mature based on skeletal age, stage of puberty) refers to the state of biological maturation of an individual at the time of observation, whereas maturity timing refers to the ages when specific maturational events are attained (ages at peak height velocity and menarche) $[11,12]$.

Among a large group of those willing to participate in the competitions in team sports, very few athletes reach the highest level of sports skills, while talent identification and qualification for a sport are based on broad criteria selected through scientific analysis [13]. Many studies have emphasized biological variability in sports for young athletes and emphasized it as one of the important aspects of talent identification and sports qualification process [14-17].

In recent years, studies of young basketball players have among others focused on the assessment of trends of anthropometric traits and physical performance [18], longitudinal changes of functional capacities [19], analyses of the effects of different training methods and protocols on power, speed, and anaerobic capacity [20-22]. Interactions between body size and composition in predicting basketball performance have also been considered [23]. These studies are often conducted independently of the maturation rate assessment and the interpretation of the performance of young athletes during adolescence is very important for coaching practice because results can be misinterpreted due to discrepancies between chronological age, biological age, and athletic age resulting from training experience [24].

From a somatic point of view, faster-maturing boys and girls are taller and heavier than their peers of the same chronological age, which gives them a huge advantage in sports involving physical contact. This variation is most noticeable between the ages of 11 and 16. Adolescence is the period in which these differences are more pronounced and the age of 13 to 16 years appears to be the most heterogeneous period $[13,16,25]$.

As a factor affecting basketball-specific functional abilities and skills, the interindividual differences in biological maturation have not been regularly evaluated, especially in young female athletes. However, research findings indicate the relative age effect on the success of youth basketball teams [26-28]. Overrepresentation of athletes born in the first months of the year in all age groups has been shown [29]. Relatively older athletes are often characterized by greater body height, which is critical in basketball [30], and an advantage in motor skills, which may bias the assessment of fitness potential of players born in different quarters of the year [31, 32]. The above correlations are most commonly reported in basketball players [30], while this effect has not been sufficiently studied in female basketball players to date. Sexual dimorphism underlies much of the physiological response to physical exercise. Physiological characteristics of girls change with age and puberty due to a different hormonal environment that begins early in fetal life [33]. Participation in an intensive training program for girls during the progressive stages of ontogenesis requires a great deal of knowledge from coaches regarding the functional abilities of young athletes in conjunction with taking care of their general health. In the case of basketball, the empirical findings on these issues are quite scarce [33]. Large differences between girls in terms of the time and pace of biological maturation can create difficulties in the correct interpretation of the rate of acquisition of individual motor and technical skills, and psychological preparation for sports competition [19].

Given the available research findings (very few concerning young female basketball players), there is a strong need for physical fitness testing in basketball on large research samples, especially to identify talents [34, 35]. Therefore, testing was carried out to evaluate the motor potential and basic anthropometric characteristics of a very large population of young female players aged 13-15 years, who were members of Polish basketball clubs. The second study aim was to show the impact of maturity timing on the results of motor tests and basic body composition. The third aim was to identify the index that mostly affects the prediction of performance in the individual tests evaluating speed, jumping ability, agility, and endurance.

\section{Methods}

\section{Participants}

The study sample size was 925 female basketball players aged 13 years $(n=277$; age: $13.05 \pm 0.28$; basketball experience: $3.0 \pm 0.8$ yrs), 14 years $(n=374$; age: $13.95 \pm 0.30$; basketball experience: $3.6 \pm 1.1 \mathrm{yrs}$ ), and 15 years $(n=274$; age: $14.82 \pm 0.28$; basketball experience: $4.3 \pm 1.3 \mathrm{yrs}$ ). All examined athletes belonged to the Caucasian ethnic group. The players were female members of 49 sports clubs competing in the national championship in the age categories U13 and U15. The U14 girls also participated in the national championships 
at the club and regional competition levels. This group included female basketball players who were members of the national team in their age categories (U13, U14, U15). All girls at this training stage (club training programs) were characterized by a similar training volume ( $8 \mathrm{~h} 45$ min per week -3 technical training sessions, $1.5 \mathrm{~h}$ each, 3 strength and conditioning sessions, $45 \mathrm{~min}$ each, and $2 \mathrm{~h}$ a week playing games) over a 8-month season (October to May). The examinations were carried out in 2017-2020 during in regular season in the same periods of the year (from November to February) to complete the measurements before the play-off phase.

\section{Procedure}

All of the participants, legal guardians, clubs and Polish Basketball Association were informed in writing about the aims, benefits, and procedure of the research project, and about the possibility to withdraw from the study at any moment. The inclusion criterion was the written informed consent obtained from each participant, and the exclusion criteria were contraindications for the basic anthropometric measurements. Injuries or trauma were also the exclusion criteria. The research was approved by the local Ethics Committee for Scientific Research (SKE 01-28/2016), and the study was conducted according to the rules and regulations of the Declaration of Helsinki [36].

\section{Biological maturation}

The APHV of the female basketball players analyzed in the study was estimated by subtracting the maturity offset from chronological age at the time of measurement [37]. The predicted maturity offset (years) was calculated as $-7.709133+(0.0042232 x$ [age $*$ stature] $)$, with standard errors of the equations of 0.542 years [38]. This equation was derived after calibrating the original equation proposed by Mirwald et al. [37]. Early maturers, average maturers, and late maturers were defined as players with an estimated APHV of less than 13.1 years, 13.1-15.1 years, and more than 15.1 years, respectively [39]. Since the average maturers accounted for $97.7 \%$ of the basketball players, it was decided to analyze only this group. Due to very low numbers, eight early maturing U13 players, four U14 players (3 early maturers, 1 late maturer), and seven U15 players (6 early maturers, 1 late maturer) were excluded from the analysis. This was followed by grouping with respect to years before/after the observed PHV0 ( -0.50 to 0.49 ), PHV1 (0.50 to 1.49 ), PHV2 (1.50 to 2.49), PHV3 (2.50 to 3.49) [39]. After this stage, the decision was made to exclude other two U13 female players from the analysis, who were the only female basketball players in the PHV0 group. Finally, 904 basketball players were considered for comparison.

\section{Measurements}

Body height $(\mathrm{cm})$ was measured barefoot with the head positioned to the Frankfurt plane, using a stadiometer (Seca 264, Seca GmbH \& co. kg, Germany) with a precision of $0.1 \mathrm{~cm}$, as were standing reach measurements (Seca 216, Seca GmbH \& co. kg, Germany). Body mass was measured using a JAWON Medical X-Scan Plus II device (Certificate No. EC0197 for medical devices) with a precision of $0.1 \mathrm{~kg}$. The measurements were taken by an anthropometry expert who holds an ISAK Level 1 accreditation according to the standards proposed by the International Society for the Advancement of Kinanthropometry (ISAK) [40]. The basic anthropometric measurements and warm-up were followed by physical fitness tests performed each time in the same order (speed test, jumping ability test, agility test, endurance test). Fitness was evaluated in two stages: the morning session (to measure speed, jumping ability, and agility), and the evening session (measurements of endurance) so that adequate rest periods were maintained.

\section{Speed}

Speed was measured using a $20 \mathrm{~m}$ sprint test with a split time recorded at $5 \mathrm{~m}$ (starting speed) and $10 \mathrm{~m}$, when players ran at full speed. Each participant performed two trials, with the best used as a test result [41]. The photoelectric cells Fusion Smart Speed System (Fusion Sport, Coopers Plains, QLD, Australia) were used to record time (s). The photocells were installed at the starting line, $5 \mathrm{~m}, 10 \mathrm{~m}$, and $20 \mathrm{~m}$. The time measurement was performed with an accuracy of $0.001 \mathrm{~s}$. Running started from the standing position, with the preferred foot positioned in front. No bouncing and backward movements were allowed before the sprint.

\section{Jumping}

The results of both standing jump (SVJ) and the a vertical jump (VJ) were measured using a yardstick vertical jump device [42-45]. The device is used to measure the height to which a player can push away small sticks placed horizontally on a pole during a jump. Reaching height was subtracted from the height reached while jumping. The first step was to perform 2 standing jump tests. Next, the player had 6 attempts ( 2 jumps with the dominant leg, 2 with the non-dominant leg, and 2 with both legs), with sufficient rests between jumps. The highest attempt scores were retained for analysis. This VJ protocol has established reliability [42-45].

\section{Agility}

The design of the agility test is presented in Fig. 1. This is a modified Lane Agility Drill [46] test, with the length 


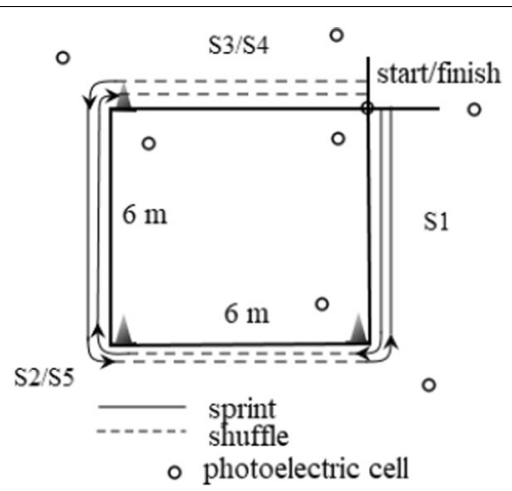

Fig. 1 Agility test design

and width changed to $6 \times 6 \mathrm{~m}$ to ensure that the proportions between defensive shuffle and sprint were identical. The position of the photocell at the change of direction line was $1 \mathrm{~m}$ from the line. The test was repeated twice, and a 10-min rest break was administered to minimize fatigue. Before the test, the participant was familiarized with the procedures by performing a trial (pre-test). The best time achieved during the test was recorded for the analysis of the results.

\section{Endurance}

The Yo-Yo Intermittent Recovery Test level 1 (Yo-Yo IR1) was used to evaluate endurance using a protocol presented in the literature [47, 48]. The total distance covered $(\mathrm{m})$ during Yo-Yo IR1 was the main measure of results and the maximum oxygen uptake $\left(\mathrm{VO}_{2} \mathrm{max}\right) \mathrm{cal}$ culated according to the formula: $\mathrm{VO}_{2} \mathrm{max}=\mathrm{IR}$ distance $(\mathrm{m}) \times 0.0084+36.4[48]$.

\section{Statistical analysis}

The normality of distribution was verified by the Shapiro-Wilk test, whereas the assumption of the equality of variance was verified using the Levene test. The reliability coefficient for the measurements was Cronbach's $\alpha=0.91$. The analysis of variance (ANOVA) was employed to show significant differences between the groups of female basketball players. Furthermore, ANCOVA analysis was used to demonstrate the differences in years after observed APHV, with chronological age, height, and mass used as covariates. Bonferroni adjustments were made for post-hoc comparisons. The effect size was evaluated using partial eta squared $\left(\eta^{2}\right)$ and classified as: no effect $=0$ to 0.039 , minimum effect $=0.04$ to 0.24 , moderate effect $=0.25$ to 0.63 , and strong effect $=\geq 0.64$ [49].

Backward stepwise multiple regression was used to estimate the relative contributions of chronological age, maturity timing (stage of APHV), body height, body mass, and height $\mathrm{x}$ mass interaction (based on residuals) to the variability of individual physical fitness tests. The significance of the effects was set at $p<0.05$ for all the analyses. All calculations were performed using STATISTICA software (v.13.3, StatSoft, USA).

\section{Results}

When analyzing the variation of female basketball players with respect to age (Table 1) in the U13 group compared to U14 and U15, there were significantly $(p<0.001$, minimum effect) lower values of age at PHV (by $0.13 /$ yrs and $0.38 / \mathrm{yrs}$, respectively; $\left.\mathrm{F}_{(2,901)}=72.1 ; \eta^{2}=0.14\right)$, body mass (by $5.5 \%$ and $7.7 \%$, respectively; $F_{(2,901)}=21.2 ; \eta^{2}=0.05$ ). In the same comparison there were also significantly $(p<0.001$, but no effect) lower values of body height $\left(1-2 \% ; \mathrm{F}_{(2,901)}=15.6 ; \eta^{2}=0.03\right)$, and arm reach $(1-2 \%$; $\left.\mathrm{F}_{(2,901)}=8.8 ; \eta^{2}=0.02\right)$. The U14 female basketball players were also characterized by lower $(p<0.001$, minimum effect) age at PHV (by $0.25 / \mathrm{yrs}$ ) compared to U15 players.

Furthermore, in the agility test, the U13 female players were slower $(p<0.001$, minimum effect) than those from U15 group in $\mathrm{S}_{4}$ (by 3.4\%; $\mathrm{F}_{(2,901)}=13.6 ; \eta^{2}=0.04$ ). The other significant differences between sprint and agility values of this two groups were without effect size. Analysis revealed that the U13 female basketball players were slower compared to U15 for $5 \mathrm{~m}$ (by $3.1 \%$; $\left.p<0.05 ; \mathrm{F}_{(2,901)}=4.6 ; \eta^{2}=0.01\right), 20 \mathrm{~m}$ (by 1.3\%; $p<0.01$; $\left.\mathrm{F}_{(2,901)}=5.8 ; \eta^{2}=0.01\right), \mathrm{S}_{3}$ (by $2.4 \% ; p<0.01 ; \mathrm{F}_{(2,901)}=6.3$; $\left.\eta^{2}=0.01\right), \mathrm{S}_{5}$ (by $\left.3.1 \% ; p<0.001 ; \mathrm{F}_{(2,901)}=9.3 ; \eta^{2}=0.02\right)$ and considering the total agility test completion time (by $\left.2.7 \% ; p<0.001 ; \mathrm{F}_{(2,901)}=9.4 ; \eta^{2}=0.02\right)$. The $\mathrm{U} 14$ group was slower than $\mathrm{U} 15$ in $\mathrm{S}_{4}$ (by $1.4 \%$, minimum effect) and total agility test completion time (by $1.5 \%$, no effect).

Analysis of the results in the context of the jumping tests showed significantly lower values $(1-5 \%)$ in $\mathrm{SVI}_{\max }$, $\mathrm{VI}_{\max }(p<0.001$; minimum effect $)$ and SVI, VJ $(p<0.01$; no effect) obtained by U13 compared to U15 players. An identical relationship (lower values within 1-4\%) was observed in $\mathrm{U} 13$ compared to $\mathrm{U} 14$ in $\mathrm{SVJ}_{\max }, \mathrm{VJ}_{\max }$, and SVJ.

Compared to U14 and U15, female basketball players from the U13 group were also characterized by significantly $(p<0.001$, but no effect) lower values of the distance covered $\left(10-14 \%, \mathrm{~F}_{(2,901)}=8.8 ; \eta^{2}=0.02\right)$ and $\mathrm{VO}_{2} \max \left(1-2 \%, \mathrm{~F}_{(2,901)}=8.3 ; \eta^{2}=0.02\right)$ in the physical capacity test.

Table 2 shows the age-adjusted characteristics of female basketball players in relation to years after PHV (Table 2). In the group of U13 basketball players who were in PHV2, significantly $(p<0.001$, minimum effect) higher values of body height (by $6.5 \% ; \mathrm{F}_{(1,263)}=28.7 ; \eta^{2}=0.18$ ), arm reach (by 6.4\%; $\mathrm{F}_{(1,263)}=18.2 ; \eta^{2}=0.12$ ) and SVJmax (by $5.4 \% ; \mathrm{F}_{(1,263)}=8.1 ; \eta^{2}=0.06$ ) were found compared 
Table 1 Descriptive statistics of female basketball players by chronological age and results of ANOVA analysis comparing age groups

\begin{tabular}{|c|c|c|c|c|c|c|c|}
\hline Variables & & $\begin{array}{l}1 . U 13 \\
(n=267)\end{array}$ & $\begin{array}{l}\begin{array}{l}2 . \text { U14 } \\
(n=370)\end{array} \\
\end{array}$ & $\begin{array}{l}\begin{array}{l}3 . \\
(n=267)\end{array} \\
\end{array}$ & $\mathrm{F}(p)$ & $n^{2}$ & d \\
\hline \multirow[t]{2}{*}{ Chronological age (years) } & M & 13.06 & 13.95 & 14.82 & - & - & - \\
\hline & S.E & 0.02 & 0.02 & 0.02 & & & \\
\hline \multirow[t]{2}{*}{ APHV (years) } & M & 11.65 & 11.78 & 12.03 & $72.1\left(^{* * *}\right)$ & 0.14 & $1 \mathrm{v} 2 \mathrm{v} 3$ \\
\hline & S.E & 0.02 & 0.02 & 0.02 & & & \\
\hline \multirow[t]{2}{*}{ Body height (cm) } & M & 165.3 & 167.7 & 167.8 & $15.6\left(^{(* *)}\right.$ & 0.03 & $1 \mathrm{v} 2,3$ \\
\hline & S.E & 0.4 & 0.3 & 0.4 & & & \\
\hline \multirow[t]{2}{*}{ Body mass (kg) } & M & 55.0 & 58.2 & 59.6 & $21.2(* * *)$ & 0.05 & $1 \mathrm{v} 2,3$ \\
\hline & S.E & 0.5 & 0.4 & 0.5 & & & \\
\hline \multirow[t]{2}{*}{ Standing reach $(\mathrm{cm})$} & M & 220.6 & 223.5 & 223.3 & $8.8\left(^{* * *}\right)$ & 0.02 & $1 v 2,3$ \\
\hline & S.E & 0.6 & 0.5 & 0.6 & & & \\
\hline \multirow[t]{2}{*}{$5 \mathrm{~m}(\mathrm{~s})$} & M & 1.243 & 1.221 & 1.205 & $4.6\left(^{*}\right)$ & 0.01 & $1 \mathrm{v} 3$ \\
\hline & S.E & 0.011 & 0.007 & 0.005 & & & \\
\hline \multirow[t]{2}{*}{$10 \mathrm{~m}(\mathrm{~s})$} & M & 2.021 & 2.028 & 2.048 & 2.2 & - & - \\
\hline & S.E & 0.012 & 0.008 & 0.007 & & & \\
\hline \multirow[t]{2}{*}{20 m (s) } & M & 3.585 & 3.551 & 3.539 & $5.8(* *)$ & 0.01 & $1 \mathrm{v} 3$ \\
\hline & S.E & 0.01 & 0.008 & 0.011 & & & \\
\hline \multirow{2}{*}{ Agility $-S_{1}(s)$} & M & 1.653 & 1.671 & 1.677 & 0.65 & - & - \\
\hline & S.E & 0.015 & 0.013 & 0.015 & & & \\
\hline \multirow[t]{2}{*}{ Agility $-S_{2}(s)$} & M & 5.768 & 5.736 & 5.672 & 2.2 & - & - \\
\hline & S.E & 0.033 & 0.027 & 0.034 & & & \\
\hline \multirow[t]{2}{*}{ Agility- $S_{3}(s)$} & M & 7.677 & 7.601 & 7.499 & $6.3(* *)$ & 0.01 & $1 \vee 3$ \\
\hline & S.E & 0.035 & 0.03 & 0.036 & & & \\
\hline \multirow[t]{2}{*}{ Agility $-S_{4}(s)$} & M & 10.082 & 9.953 & 9.754 & $13.6\left(^{(* * *)}\right.$ & 0.04 & $1,2 \mathrm{v} 3$ \\
\hline & S.E & 0.045 & 0.04 & 0.043 & & & \\
\hline \multirow[t]{2}{*}{ Agility $-S_{5}(s)$} & M & 13.678 & 13.471 & 13.272 & $9.3\left(^{* * *}\right)$ & 0.02 & $1 \vee 3$ \\
\hline & S.E & 0.063 & 0.059 & 0.064 & & & \\
\hline \multirow[t]{2}{*}{ Agility_Total (s) } & M & 15.726 & 15.538 & 15.314 & $9.4\left(^{* * *}\right)$ & 0.02 & $1,2 \mathrm{v} 3$ \\
\hline & S.E & 0.068 & 0.059 & 0.062 & & & \\
\hline \multirow[t]{2}{*}{$S V J_{\max }(\mathrm{cm})$} & $M$ & 255.3 & 259.8 & 260.0 & $17.7\left(^{* * *}\right)$ & 0.04 & $1 \mathrm{v} 2,3$ \\
\hline & S.E & 0.7 & 0.6 & 0.6 & & & \\
\hline \multirow[t]{2}{*}{$\mathrm{VJ}_{\max }(\mathrm{cm})$} & M & 263.7 & 268.1 & 268.7 & $15.6\left(^{* * *}\right)$ & 0.04 & $1 \mathrm{v} 2,3$ \\
\hline & S.E & 0.7 & 0.6 & 0.7 & & & \\
\hline \multirow[t]{2}{*}{ SVJ (cm) } & M & 34.9 & 36.2 & 36.7 & $7.07\left(^{* *}\right)$ & 0.02 & $1 v 2,3$ \\
\hline & S.E & 0.3 & 0.3 & 0.4 & & & \\
\hline \multirow[t]{2}{*}{ VJ $(\mathrm{cm})$} & M & 43.1 & 44.5 & 45.3 & $5.69\left(^{* *}\right)$ & 0.01 & $1 \mathrm{v} 3$ \\
\hline & S.E & 0.5 & 0.4 & 0.5 & & & \\
\hline \multirow[t]{2}{*}{ Yo-Yo Distance (m) } & M & 736 & 826 & 852 & $8.8\left(^{* * *}\right)$ & 0.02 & $1 \mathrm{v} 2,3$ \\
\hline & S.E & 20 & 18 & 22 & & & \\
\hline \multirow[t]{2}{*}{$Y_{O}-Y_{O} V_{O_{2 \max }}(\mathrm{ml} / \mathrm{kg} / \mathrm{min})$} & M & 42.6 & 43.3 & 43.4 & $8.3\left(^{(* *}\right)$ & 0.02 & $1 \mathrm{v} 2,3$ \\
\hline & S.E & 0.2 & 0.1 & 0.2 & & & \\
\hline
\end{tabular}

$\mathrm{M}$ mean; S.E. standard errors; SVJ standing vertical jump; VJ vertical jump; $\mathrm{d}$ significant differences between groups ${ }^{*} p<0.05,{ }^{* *} p<0.01,{ }^{* * *} p<0.001$

to PHV1. In the same comparison there were also significantly $(p<0.05$, but no effect) higher values of VJmax (by $4.7 \% ; p<0.05 ; \mathrm{F}_{(1,263)}=3.7 ; \eta^{2}=0.03$ ). In contrast, the PHV2 group performed worse in the $5 \mathrm{~m}$ sprint test (by $2.3 \% ; p<0.01 ; \mathrm{F}_{(1,263)}=5.5 ; \eta^{2}=0.04 ;$ minimum effect) and endurance test, both in terms of the distance covered and $\mathrm{VO}_{2} \max \left(2-13 \% ; p<0.05 ; \mathrm{F}_{(1,263)}=3.3 ; \eta^{2}=0.02\right.$; no effect).

Furthermore, compared to groups PHV1 and PHV2, U14 female basketball players in PHV3 had higher 


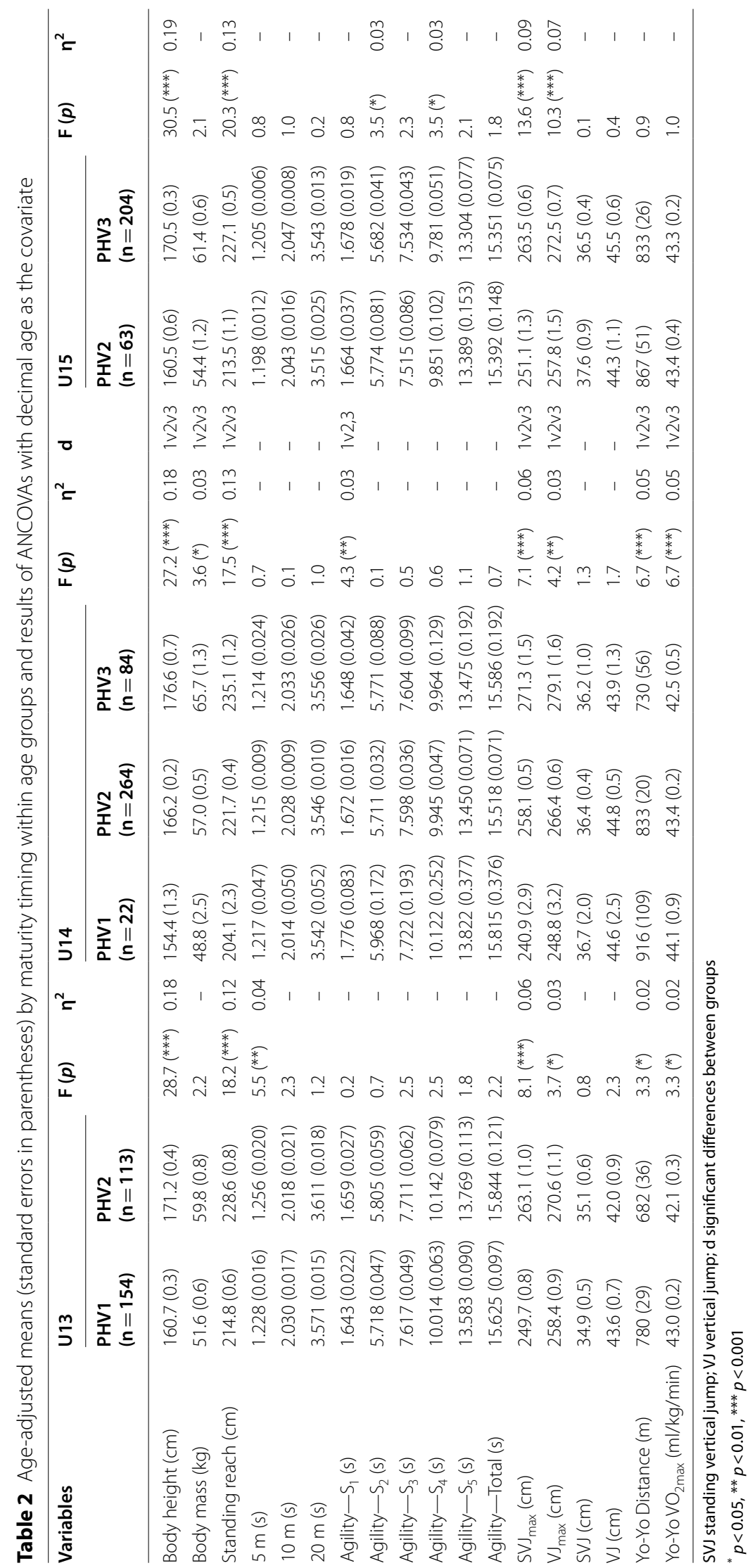


( $p<0.001$, minimum effect) body height (by $14.4 \%$ and $6.3 \%$, respectively; $\left.F_{(2,364)}=27.2 ; \eta^{2}=0.18\right)$, arm range (by $15.2 \%$ and $6 \%$, respectively; $\mathrm{F}_{(1,263)}=17.5 ; \eta^{2}=0.13$ ), $\mathrm{SVI}_{\max }$ (by $12.6 \%$ and $5.1 \%$ respectively; $\mathrm{F}_{(2,364)}=7.1$; $\left.\eta^{2}=0.06\right)$. In the same comparison there were also significantly (but no effect) higher values of body mass (by $34.6 \%$ and $8.7 \%$, respectively; $p<0.05 ; \mathrm{F}_{(2,364)}=3.6$; $\eta^{2}=0.03$ ) and $\mathrm{VJ}_{\max }$ (by $12.6 \%$ and $4.8 \%$, respectively; $\left.p<0.01 ; \mathrm{F}_{(2,364)}=4.2 ; \eta^{2}=0.03\right)$. An identical trend was recorded in the same variables in favor of PHV2 compared to PHV1, ranging from 7 to $17 \%$. Compared to PHV1 and PHV2, significantly lower values $(p<0.001$; $\mathrm{F}_{(2,364)}=6.7 ; \eta^{2}=0.05$; minimum effect) of distance covered (by $20.3 \%$ and $12.4 \%$, respectively) and $\mathrm{VO}_{2} \max$ (by $3.6 \%$ and $2.1 \%$, respectively) in endurance test were observed in the PHV3 group. Also in these two parameters, favorable results were obtained by the PHV1 group compared to PHV2 (1-10\%).

Compared to PHV2, the U15 basketball players from group PHV3 showed higher $(p<0.001$, minimum effect) values of body height (by $6.2 \% ; \mathrm{F}_{(1,263)}=30.5 ; \eta^{2}=0.19$ ), arm reach (by 6.4\%; $\mathrm{F}_{(1,263)}=20.3 ; \eta^{2}=0.13$ ), $\mathrm{SVI}_{\max }$ (by $4.9 \% ; \quad \mathrm{F}_{(1,263)}=13.6 ; \eta^{2}=0.09$ ), $\mathrm{VJ}_{\max }$ (by $5.7 \%$; $\left.\mathrm{F}_{(1,263)}=10.3 ; \eta^{2}=0.07\right)$. More favorable results $(\mathrm{p}<0.05$, but no effect) were observed in two sections of the agility test $\mathrm{S}_{2}, \mathrm{~S}_{4}$ (within 1-2\%; $\mathrm{F}_{(1,263)}=3.5 ; \eta^{2}=0.03$ ).

Comparison of age-, height-, and weight-adjusted means (ANCOVA) with reference to years after PHV (Table 3) showed favorable results in $20 \mathrm{~m}$ sprint test and higher results in all jumping ability and endurance tests $(1-6 \%)$ in the group of U13 female basketball players in PHV1. An identical trend of higher values (minimum effect) was observed in U14 female players in PHV1 compared to PHV2 and PHV3 in arm reach $(1-2 \% ; p<0.05)$, $\mathrm{SVI}_{\max }(7-9 \% ; p<0.01), \mathrm{VJ}_{\max }(1-3 \%, p<0.01)$ and a more favorable result in the $20 \mathrm{~m}$ sprint test $(2-5 \% ; p<0.01)$. In the same comparison there was also significantly (by $42-53 \%$; $p<0.05$, but no effect) higher value of SVJ. The opposite trend $(\mathrm{p}<0.01$, minimum effect) was observed for distance covered during the endurance test (by $17-19 \%$ ), $\mathrm{VO} 2_{\max }$ (by $12-13 \% ; p<0.01$ ) and $5 \mathrm{~m}$ sprint (by $3-10 \%$; $p<0.05$; but no effect). Compared to PHV3, U15 basketball players from the PHV2 group were characterized by lower values of all variables of jumping abilities $(1-10 \%)$, endurance $(3-15 \%)$, and weaker time in $10 \mathrm{~m}$ and $20 \mathrm{~m}$ speed tests $(1-3 \%)$, and on the S4 section and in the entire agility test (2-4\%).

The results of the backward stepwise multiple regression analysis are presented in Table 4. The presented model explained $2-10 \%$ of the variance in individual strength and conditioning tests (adjusted $R^{2}=0.02-0.10$; $p<0.001$ ). The time from PHV was a significant predictor (positive value of the normalized $\beta$ coefficient) only for the $10 \mathrm{~m}$ test. Furthermore, age was a significant predictor for the $5 \mathrm{~m}$ speed test, $20 \mathrm{~m}$ speed test, agility test (negative $\beta$ coefficient), and SVJ, VJ, and $\mathrm{VO}_{2} \mathrm{max}$ (positive $\beta$ coefficient) tests. The predictor of interactions of body height and body mass was significant only for the SVJ test (negative coefficient $\beta$ ). Body mass alone was a significant predictor in the $10 \mathrm{~m}$ and $20 \mathrm{~m}$ tests (positive direction) and $\mathrm{VJ}, \mathrm{VO}_{2} \max$ (negative direction). It was also found that body height was a significant predictor only in the $10 \mathrm{~m}$ speed test.

\section{Discussion}

The aims of this study were (1) to identify the physical fitness and basic anthropometric characteristics of Polish female basketball players aged 13 to 15 years, (2) to show the effect of maturity timing on the performance in motor tests and basic body composition parameters, (3) to identify the index that contributes most to the prediction of performance in the tests of sprint, jumping ability, agility, and endurance.

The first aim of the study was to identify motor potential and basic anthropometric characteristics of the population of young female basketball players aged 13-15 years. Determination of these parameters is a starting point in the search for candidates for the participant of national teams or defining the characteristics needed or conducive to high performance. Talent identification programs are an integral part of the selection process for elite-level athletes and every sport has its set of variables being an important part of success [50]. Many sports clubs have their individual systems of selection according to the most important features in a given discipline or event. This rationale underlies the emergence of various recruitment and selection programs aimed at seeking, identifying, and developing talented individuals [51, 52]. Polish female basketball players from the U15 group achieved slightly better (compared to peers, the best basketball female players in Europe, participating in the youth championships of European Division A), or identical results (compared to female basketball players participating in the youth championships of European Division B) in 20 m sprint test [53]. Further, Polish female athletes were characterized by lower values of body height and body mass. On the other hand, a comparison of the values after correcting with body height revealed no significant differences [53]. Such a trend may indicate that the Polish players are more similar to their peers from Division B (2nd European League) teams than to Division A (1st European League). The basketball players from the U13 group also achieved better results (even considering age-adjusted values) in the $20 \mathrm{~m}$ sprint compared to their peers from Portugal [7]. 


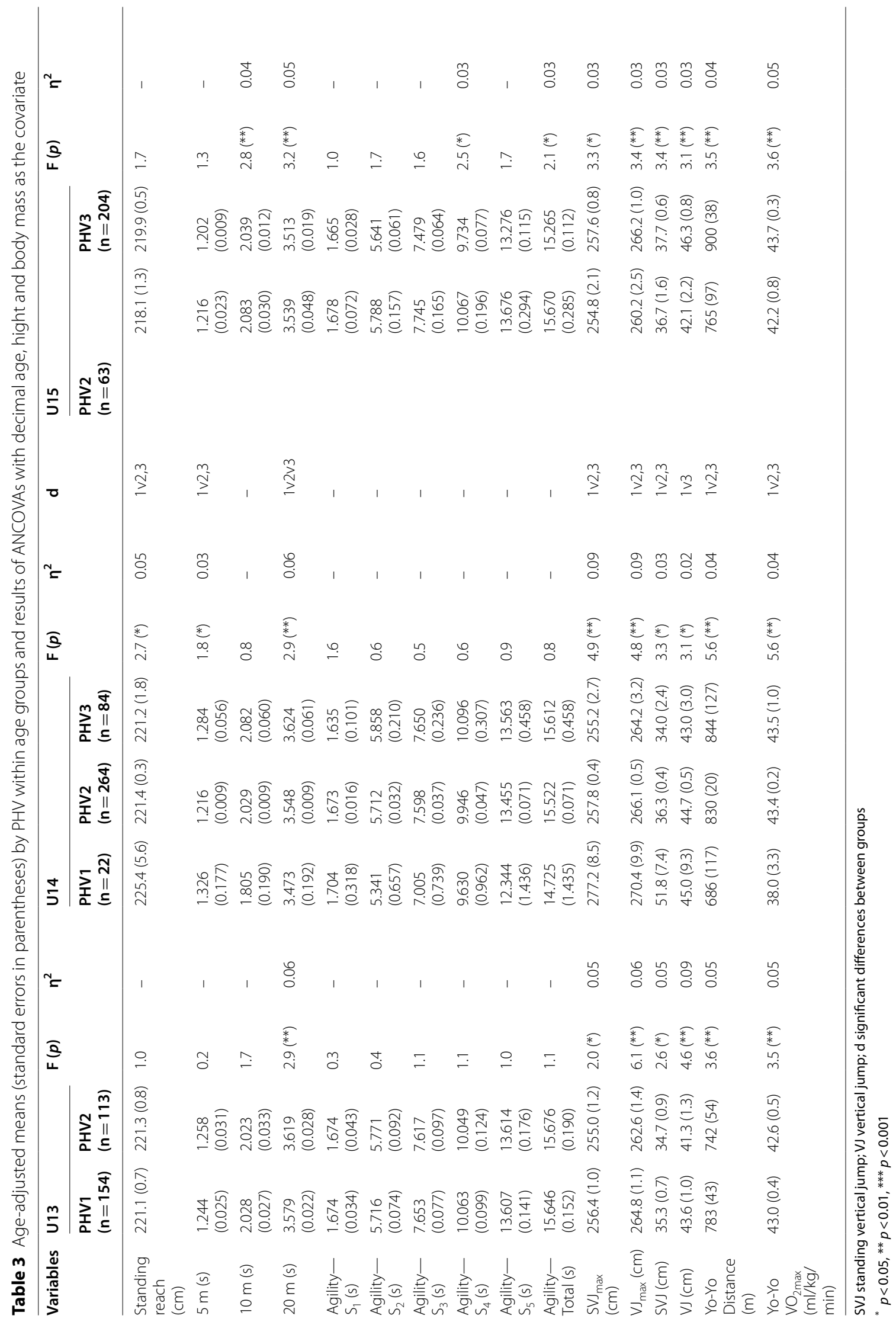


Table 4 Summary of the backward regression for motor skills and anthropometric variables by the female basketball players aged 13-15 years

\begin{tabular}{|c|c|c|c|c|}
\hline Attempt & Predictor & Standardized $\beta$ & Adjusted $\mathrm{R}^{2}$ & $F(p)$ \\
\hline $5 \mathrm{~m}$ & Chronological age & -0.111 & 0.02 & $11.2(*)$ \\
\hline \multirow[t]{3}{*}{$10 \mathrm{~m}$} & Body height & -0.161 & 0.02 & $7.2\left(^{*}\right)$ \\
\hline & Body mass & 0.154 & & \\
\hline & APHV & 0.100 & & \\
\hline \multirow[t]{2}{*}{$20 \mathrm{~m}$} & Chronological age & -0.156 & 0.06 & $27.1\left(^{*}\right)$ \\
\hline & Body mass & 0.214 & & \\
\hline Agility $_{\text {Total }}$ & Chronological age & -0.160 & 0.03 & $23.7\left(^{*}\right)$ \\
\hline \multirow[t]{2}{*}{ SVJ } & Chronological age & 0.161 & 0.04 & $17.2(*)$ \\
\hline & Mass*height interaction & -0.143 & & \\
\hline \multirow[t]{2}{*}{ VJ } & Chronological age & 0.170 & 0.06 & $26.5\left(^{*}\right)$ \\
\hline & Body mass & -0.201 & & \\
\hline \multirow[t]{2}{*}{$Y_{O}-Y_{O} V_{2}{ }_{2 \max }$} & Chronological age & 0.201 & 0.10 & $42.8\left(^{*}\right)$ \\
\hline & Body mass & -0.261 & & \\
\hline
\end{tabular}

SVJ standing vertical jump; VJ vertical jump

${ }^{*} p<0.001$

The second study aim was to show the impact of maturity timing on the results of motor tests and basic body composition. Somatic built and physical fitness potencial determines, on the one hand, factors necessary to qualify an athlete for a given sport and, on the other hand, having optimal parameters for success in the sport. Analysis of values related to age-adjusted characteristics showed that in the PHV2 under 13-year-old group observed significantly higher $\mathrm{SVI}_{\max }, \mathrm{VI}_{\max }$ values but worse sprint $(5 \mathrm{~m})$ and endurance results (distance covered, $\mathrm{VO}_{2 \max }$ ) than PHV1 group. U14 female basketball players in PHV3 had significantly higher $\mathrm{SVI}_{\max }, \mathrm{VI}_{\max }$ results compared to groups PHV1 and PHV2 and lower values of endurance test (distance covered and $\mathrm{VO} 2_{\max }$ ). Limited study suggest that less mature girls perform better than more maturing girls in some tasks, but overall maturity-associated variation is not consistent across tasks and ages [54]. The U15 basketball players from PHV3 compared to PHV 2 group showed higher values of $\mathrm{SVI}_{\max }, \mathrm{VJ}_{\max }$ and agility test $\left(\mathrm{S}_{2}, \mathrm{~S}_{4}\right)$. This is consistent with previous researche where more mature players are typically characterized by higher performance in speed, agility, and lower limb power $[7,55]$.

Similar trend was shown in ANCOVA results (age, body height, and body mass as covariates) where in the U13 female basketball players observed significantly higher sprinting $(20 \mathrm{~m})$, jumping ability and endurance tests results of the PHV1 group. Better results was observed in U14 female players in PHV1 compared to PHV2 and PHV3 in $20 \mathrm{~m}$ and jumping tests but opposite trend was observed for $5 \mathrm{~m}$ sprint and endurance test (distance covered and $\mathrm{VO} 2_{\max }$ ). $\mathrm{U} 15$ basketball players from the PHV3 group were characterized by better results of jumping abilities, endurance, $10 \mathrm{~m}$ and $20 \mathrm{~m}$ sprint and agility (total, $\mathrm{S}_{4}$ ) tests. In this context, it is important to take biological development into account, since differences resulting from this development are most often overlooked and thus early maturers are promoted. Selection carried out in this way is often flawed if decisions are made before the maturation process is complete [56].

The third aim of the study, which was to identify the indices most useful in predicting the level of motor preparation, allowed for the conclusion that chronological age, height, weight, weight-height interaction, and the time from PHV accounted for $2-10 \%$ of the variance in individual physical fitness tests. Maturity timing was a significant predictor only in sprint test $(10 \mathrm{~m})$ but body height and body mass were the most significant predictors in this test. Rest results showed that chronological age $\left(5 \mathrm{~m}, 20 \mathrm{~m}\right.$, agility, SVJ, VJ, and $\mathrm{VO}_{2 \max }$ tests), body height $(10 \mathrm{~m})$, body mass $\left(10 \mathrm{~m}, 20 \mathrm{~m}, \mathrm{VJ}, \mathrm{VO}_{2 \max }\right)$, and the interaction between body mass and height (SVI) were significant (adjusted $R^{2}=0.02-0.10 ; p<0.001$ ) predictors of motor skills. In general, considering the adjusted $\mathrm{R}^{2}$ value, most of the differences in the results obtained by female basketball players were not explained by these variables. There is extensive literature on the analysis of selected motor and functional fitness characteristics in correlation with the level of physical development in adolescent girls, however mainly in general non-athlete populations $[57,58]$. In contrast, the results of our study are consistent with previous findings and show that much of the variation in sport-specific functional abilities and 
skills is not explained by age, puberty, and body size [ 8 , $10]$ and for young training girls, understanding the complex interactions of physical development, especially body mass and height, with sport-specific motor abilities and biological age is a key component of sporting success [7].

The objectivity of inferring developmental capabilities depends largely on a comprehensive assessment of the status of various functional systems involved in a specialized task. Such an assessment of physical and mental preparation, in addition to the generally accepted indicators, should take into account chronological, biological, and sport age (accumulated training and competitive experience in sport) [19], individual rate of performance development, indicators of physical development and motor activity at the stage before the examination and the assessment of their prospective capabilities [59]. Particular caution should be exercised in the selection based on index values obtained before puberty. Most of the changes occurring during puberty (e.g. aerobic and anaerobic capacity, fitness, body composition) are nonlinear [60]. Results showed that only a third of international pre-junior athletes reappeared as senior athletes, confirming the difficulties of predicting late success based on early identification and selection [61].

Further, both somatic, motor and developmental parameters should not be treated as an absolute selection criterion, especially in sports where the results are an effect of multidimensional dependencies of various variables [62]. The superior performance here may result from individually varying relationships between innate determinants of athletic performance and environmental factors [59].

The most important limitation of the present study was not including the menarche age. However, we know from other studies that menarche is a late adolescent event that occurs, on average maturers, about a year or so after PHV $[63,64]$. This regularity was also confirmed by longitudinal studies of Polish girls $(n=176$, Polish ancestry, Poznań growth study) where the mean time interval between PHV and menarche was 1.28 years [64]. At Kaczmarek's study age at menarche was only weakly correlated with height at critical points of the adolescent spurt and reversely correlated with velocity - the earlier the menarche the higher the height velocity [64]. In other longitudinal studies of trained girls $(n=23)$ and their untrained peers $(n=26$; Polish ancestry, Warsaw growth study) interval between PHV and menarche was $1.2 \pm 0.6$ and $1.1 \pm 0.5$, respectively [63]. Peak height velocity and menarche occur, on average maturers, slightly later in trained girls (APHV-12.0 \pm 0.8 active; $11.8 \pm 0.7$ non active), but the differences were not significant [63]. In another study of USA population $(n=156,80.6 \%$-white race and 19.4\%-nonwhite race) the mean age at PHV was $12.1 \pm 1.4$ years for females and the majority of girls (69.1\%) had achieved PHV by Tanner stage 3 [65].

Another limitation of present study was that we did not account for factors that may influence linear growth and pubertal timing such as obesity, which can accelerate puberty in girls [66]. In our study did not also consider analysis depending on sport age (accumulated training and competitive experience in sport) [19]. Finally, all equations used to predict APHV (maturity shift) or APHV have the same major limitations $[67,68]$. The advanced maturity timing and the relatively narrow range of variation in predicted age at peak height velocity may undermine its utility and effectiveness in talent identification and development programs when applied at a specific time point $[6,15]$.

Given the above, it seems that knowledge of APHV of players is important to identify differences in motor potential caused by developmental changes [69]. However, it must be complemented by the use of methods related to the evaluation of technique within individual specializations [70]. Another concern to consider is the using of methods to assess the effect of body size (tridimensional charactersitics of players) on performance fitness test results, such as allometric scaling. In future studies of this type, especially considering adolescent girls' groups, an attempt should be made to combine factors determining performance, such as hormonal status, body components, perceptual-cognitive elements, tactical skills, and sport age. Study the relation of APHV and performance using Bayesian methods should be provided to interpretation about trends of outcomes and controlling the influences of multilevel clustering [19]. Finally, longitudinal studies of a group of female basketball players are desirable in order to describe their career progression (whether they reach or not professional level, drop-out from discipline and why), in or between seasons comparison, assess some psychological dimensions (to understand what relationships are the most important in the young players development).

\section{Conclusions}

The results of this study improve our understanding how maturity timing influences on the performance in motor tests and basic body composition parameters in youth female basketball players. The status of reference to years after PHV has a particular effect on performance during jumping test, endurance test, and $20 \mathrm{~m}$ speed test in all three (U13-U15) age categories. The time from peak height velocity (PHV) was a significant predictor only in the $10 \mathrm{~m}$ speed test, but height and weight were the most significant. Chronological age $(5 \mathrm{~m}, 20 \mathrm{~m}$, agility, SVI, $\mathrm{VI}$, and $\mathrm{VO}_{2 \max }$ tests), body height $(10 \mathrm{~m})$, body mass 
$\left(10 \mathrm{~m}, 20 \mathrm{~m}, \mathrm{VJ}, \mathrm{VO}_{2 \max }\right)$, and the interaction between body mass and height (SVI) were significant predictors of motor skills. The results can help the coaches to personalize training programs and to adapt the training content to the biological age of the players.

\section{Abbreviations}

APHV: Age at peak height velocity; PHV: Peak height velocity; SVJ: Standing vertical jump; VJ: Vertical jump.

\section{Acknowledgements}

The author would like to thank the Polish Basketball Association for their assistance in this study.

\section{Authors' contributions}

Research concept and study design: KG, JGA, AK, JLC, ALC, KM. Literature review: KG, JLC ALC. Data collection: KG, JGA, AK. Data analysis and interpretation: KG, AK, KM. Statistical analyses: KG, JGA, JLC. Writing of the manuscript: KG, JGA, AK, JLC, ALC, KM. Review and editing: KG, JGA, AK, JLC, ALC, KM. All authors read and approved the final manuscript.

\section{Funding}

No funding was received.

Availability of data and materials

Full access to data on request (karol.gryko@awf.edu.pl).

\section{Declarations}

\section{Ethics approval and consent to participate}

The research was conducted in accordance with the approval from the local Ethics Committee for Scientific Research of the University of Physical Education in Warsaw (SKE 01-28/2016), and the study was completed according to the rules and regulations of the Declaration of Helsinki.

\section{Consent for publication}

Not applicable.

\section{Competing interests}

The authors declare that they have no competing interests.

\section{Author details}

'Department of Sport Games, Józef Piłsudski University of Physical Education in Warsaw, Marymoncka 34, 00-968 Warsaw, Poland. ${ }^{2}$ Department of Theory of Sport, Józef Pilsudski University of Physical Education in Warsaw, Marymoncka 34, 00-968 Warsaw, Poland. ${ }^{3}$ Department of Human Biology, Józef Pilsudski University of Physical Education in Warsaw, Marymoncka 34, 00-968 Warsaw, Poland. ${ }^{4}$ Department of Sports, Faculty of Physical Activity and Sport, Universidad Politécnica de Madrid, Madrid, Spain. ${ }^{5}$ Department of Basketball and Football, Jerzy Kukuczka Academy of Physical Education, Katowice, Poland.

Received: 26 November 2021 Accepted: 1 February 2022

Published online: 08 February 2022

\section{References}

1. Drinkwater EJ, Pyne DB, McKenna MJ. Design and interpretation of anthropometric and fitness testing of basketball players. Sports Med. 2008;38:565-78

2. Nowak A, Pytel A, Molik B, Marszałek J. Characteristics of injuries of young adult male basketball players. Adv Rehabilit. 2019;33(3):35-46. https://doi. org/10.5114/areh.2019.87747.

3. Gryko K, Mikołajec K, Marszałek J, Adamczyk JG, Molik B, Waśkiewicz Z Nikolaidis P, Knechtle B. How did basketball teams win EuroBasket 2015? A non-standard analysis of performance based on passes, dribbling and turnovers. Int J Perform Anal Sport. 2020;20(3):339-56. https://doi.org/10. 1080/24748668.2020.1749013.

4. Ziv G, Lidor R. Physical attributes, physiological characteristics, on-court performances and nutritional strategies of female and male basketball players. Sports Med. 2009;39(7):547-68. https://doi.org/10.2165/00007 256-200939070-00003.

5. Arede J, Ferreira AP, Gonzalo-Skok O, Leite N. Maturational development as key aspect in physical performance and National Team Selection in Elite Male Basketball Players. Int J Sports Physiol Perform. 2018;20:1-24.

6. Arede J, Fernandes J, Moran J, Norris J, Leite N. Maturity timing and performance in a youth national basketball team: Do early-maturing players dominate? Int J Sports Sci Coach. 2021;16(3):722-30. https://doi.org/10. $1177 / 1747954120980712$.

7. Arede J, Oliveira I, Ángel Gomez MA, Leite N. A multi-block multivariate analysis to explore the influence of the somatic maturation in youth basketball. Front Psychol. 2021;12: 602576. https://doi.org/10.3389/fpsyg. 2021.602576

8. Coelho E, Silva MJ, Moreira Carvalho H, Gonçalves CE, Fiqueiredo AJ, Elferink-Gemser MT, Philippaerts RM, Malina RM. Growth, maturation, functional capacities and sport-specific skills in 12-13 year-old- basketball players. J Sports Med Phys Fitness. 2010;50(2):174-81.

9. Weaving $D$, Jones B, Till K, Abt G, Beggs C. The case for adopting a multivariate approach to optimize training load quantification in team sports. Front Physiol. 2017;8:1024. https://doi.org/10.3389/fphys.2017.01024.

10. Malina RM, Cumming SP, Kontos AP, Eisenmann JC, Ribeiro B, Aroso J. Maturity-associated variation in sport-specific skills of youth soccer players aged 13-15 years. J Sports Sci. 2005;23(5):515-22. https://doi.org/10. 1080/02640410410001729928.

11. Malina RM, Bouchard C, Bar-Or O. Growth, maturation, and physical activity. 2nd ed. Champaign: Human Kinetics; 2004.

12. Myburgh GK, Cumming SP, Malina RM. Cross-sectional analysis investigating the concordance of maturity status classifications in Elite Caucasian Youth Tennis Players. Sports Med Open. 2019;5(1):27. https://doi.org/10. 1186/s40798-019-0198-8.

13. Gonçalves CEB, Rama LML, Figueiredo AB. Talent identification and specialization in sport: an overview of some unanswered questions. Int J Sports Physiol Perform. 2012;7(4):390-3. https://doi.org/10.1123/ijspp.7.4 390.

14. Guimarães E, Baxter-Jones ADG, Williams AM, Tavares F, Janeira MA, Maia $J$. The role of growth, maturation and sporting environment on the development of performance and technical and tactical skills in youth basketball players: The INEX study. J Sports Sci. 2021;39(9):979-91. https:// doi.org/10.1080/02640414.2020.1853334.

15. Ramos SA, Massuça LM, Volossovitch A, Ferreira AP, Fragoso I. Morphological and fitness attributes of young male portuguese basketball players: normative values according to chronological age and years from peak height velocity. Front Sports Active Living. 2021;3: 629453. https://doi. org/10.3389/fspor.2021.629453.

16. Malina RM. Growth and maturity status of young soccer players. In: Reilly T, Williams AM, editors. Science and soccer. London: Routledge; 2003. p. 287-306.

17. Torres-Unda J, Zarrazquin I, Gravina L, Zubero J, Seco J, Gil S, Gil J, Irazusta J. Basketball performance is related to maturity and relative age in elite adolescent players. J Strength Cond Res. 2016;30:1325-32.

18. Drinkwater EJ, Hopkins WG, McKenna MJ, Hunt PH, Pyne DB. Modelling age and secular differences in fitness between basketball players. J Sports Sci. 2007;25(8):869-78. https://doi.org/10.1080/02640410600907870.

19. Carvalho HM, Leonardi TJ, Soares ALA, Paes RR, Foster C, Gonçalves CE. Longitudinal changes of functional capacities among adolescent female basketball players. Front Physiol. 2019. https://doi.org/10.3389/fphys. 2019.00339.

20. Balčiūnas M, Stonkus S, Abrantes C, Sampaio J. Long term effects of different training modalities on power, speed, skill and anaerobic capacity in young male basketball players. J Sports Sci Med. 2006;5(1):163-70.

21. Vučković I, Gadžić A, Sladojević V, Kukrić A, Mikić M, Stojanović M. Influence of a pre-shot dynamic stretching routine on free throw performance. Biomed Human Kinetic. 2019;11(1):181-8. https://doi.org/10. 2478/bhk-2019-002.

22. Arede J, Leite N, Bradley B, Madruga-Parera M, Saéz de Villarreal E, Gonzalo-Skok O. Mechanical, physiological, and perceptual demands of repeated power ability lower-body and upper-body tests in youth 
athletes: somatic maturation as a factor on the performance. Front Psychol. 2020;11:1888. https://doi.org/10.3389/fpsyg.2020.01888

23. Nedeljkovic A, Mirkov DM, Kukolj M, Ugarkovic D, Jaric S. Effect of maturation on the relationship between physical performance and body size. J Strength Cond Res. 2007;21(1):245-50.

24. McNarry MA, Lester L, Brown J, Mackintosh KA. Investigating the modulatory role of chronological and biological age on performance predictors in youth swimmers. J Sci Sport Exercise. 2020;2:349-58. https://doi.org/10.1007/s42978-020-00082-1.

25. Baxter-Jones ADG, Eisenmann JC, Sherar LB. Controlling for maturation in pediatric exercise science. Pediatr Exerc Sci. 2005;17(1):18-30.

26. Rubajczyk K, Świerzko K, Rokita A. Doubly disadvantaged? The relative age effect in Poland's basketball players. J Sports Sci Med. 2017;16(2):280-5.

27. de la Rubia RA, Lorenzo Calvo J, Mon-López D, Lorenzo A. Impact of the relative age effect on competition performance in basketball: a qualitative systematic review. Int J Environ Res Public Health. 2020:17(22):8596. https://doi.org/10.3390/ijerph17228596.

28. Kelly AL, Jiménez Sáiz SL, Lorenzo Calvo A, de la Rubia A, Jackson DT, Jeffreys MA, Ford C, Owen D, Santos SDLD. Relative age effects in basketball: exploring the selection into and successful transition out of a National Talent Pathway. Sports. 2021;9:101. https://doi.org/10.3390/ sports9070101.

29. Arrieta H, Torres-Unda J, Gil SM, Irazusta J. Relative age effect and performance in the U16, U18 and U20 European basketball championships. J Sports Sci. 2016;34:1530-4.

30. Torres-Unda J, Zarrazquin I, Gil J, Ruiz F, Irazusta A, Kortajarena M, Seco J, Irazusta J. Anthropometric, physiological and maturational characteristics in selected elite and non-elite male adolescent basketball players. J Sports Sci. 2013;31:196-203.

31. Lockie RG, Jeffriess MD, McGann TS, Callaghan SJ, Schultz AB. Planned and reactive agility performance in semiprofessional and amateur basketball players. Int J Sports Physiol Perform. 2014;9:766-71.

32. Sisic N, Jelicic M, Pehar M, Spasic M, Sekulic D. Agility performance in high-level junior basketball players: the predictive value of anthropometrics and power qualities. J Sports Med Phys Fitness. 2016;56:884-93.

33. Mcmanus AM, Armstrong N. Physiology of elite young female athletes. Med Sport Sci. 2011;56:23-46. https://doi.org/10.1159/000320626.

34. te Wierike SC, de Jong MC, Tromp EJ, Vuijk PJ, Lemmink KA, Malina RM, Elferink-Gemser MT, Visscher C. Development of repeated sprint ability in talented youth basketball players. J Strength Cond Res. 2014;28(4):928-34. https://doi.org/10.1097/JSC.0000000000000223.

35. Jakovljević S, Pajić Z, Gardašević B, Višnjić D. Some anthropometric and power characteristics of 12 and 13 years old soccer and basketball players. Proceedings 2010. 2011;2:42-48. https://doi.org/10.5550/SP.2. 2010.06

36. Association WM. World Medical Association Declaration of Helsinki. Ethical principles for medical research involving human subjects. Bull World Health Organ. 2001;79:373-4.

37. Mirwald RL, Baxter-Jones ADG, Bailey DA, Beunen GP. An assessment of maturity from anthropometric measurements. Med Sci Sports Exerc. 2002;34(4):689-94. https://doi.org/10.1097/00005768-200204000-00020.

38. Moore SA, McKay HA, Macdonald H, Nettlefold L, Baxter-Jones AD, Cameron N, Brasher PM. Enhancing a somatic maturity prediction model. Med Sci Sports Exerc. 2015;47:1755-64.

39. Kozieł S, Malina RM. Modified maturity offset prediction equations: validation in independent longitudinal samples of boys and girls. Sports Med. 2018:48:221-36.

40. Marfell-Jones MJ, Stewart AD, De Ridder JH. International standards for anthropometric assessment. Wellington, New Zealand: International Society for the Advancement of Kinanthropometry; 2012.

41. Kirkendall D, Gruber J, Johnson R. Measurement and evaluation for physical educators; human kinetics. Champaign. USA: IL; 1987.

42. Buckthorpe M, Morris J, Jonathan P. Folland. Validity of vertical jump measurement devices. J Sports Sci. 2012;30(1):63-9. https://doi.org/10. 1080/02640414.2011.624539.

43. Brooks ER, Benson AC, Bruce LM. Novel technologies found to be valid and reliable for the measurement of vertical jump height with jump-andreach testing. J Strength Cond Res. 2018;32(10):2838-45. https://doi.org/ 10.1519/jsc.0000000000002790.
44. Gabbett T, Kelly J, Pezet T. Relationship between physical fitness and playing ability in rugby league players. J Strength Cond Res. 2007;21(4):112633. https://doi.org/10.1519/r-20936.1.

45. Coutts AJ, Reaburn P, Piva TJ, Rowsell GJ. Monitoring for overreaching in rugby league players. Eur J Appl Physiol. 2007;99:313-24.

46. Gryko K. Effect of maturity timing on the physical performance of male Polish basketball players aged 13 to 15 years. Sci Rep. 2021;11:22019. https://doi.org/10.1038/s41598-021-01401-4.

47. Bangsbo J, laia FM, Krustrup P. The Yo-Yo intermittent recovery test: a useful tool for evaluation of physical performance in intermittent sports. Sports Med. 2008;38(1):37-51. https://doi.org/10.2165/00007256-20083 8010-00004 (PMID: 18081366)

48. Fort-Vanmeerhaeghe A, Montalvo A, Latinjak A, Unnithan V. Physical characteristics of elite adolescent female basketball players and their relationship to match performance. J Hum Kinet. 2016;53:167-78.

49. Hopkins W. A scale of magnitudes for effect statistics. Sports Science. 2006, Retrieved from http://www.sportsci. org/resource/stats/effectmag.html

50. Johnston K, Wattie N, Schorer J, Baker J. Talent identification in sport: a systematic review. Sports Med. 2018;48:97-109. https://doi.org/10.1007/ s40279-017-0803-2.

51. Balyi I, Hamilton A. Long-Term Athlete Development: Trainability in Childhood and Adolescence. Windows of Opportunity. Optimal Trainability. Victoria, British Columbia, Canada: National Coaching Institute British Columbia and Advanced Training and Performance Ltd, 2004.

52. Ford P, De Ste CM, Lloyd R, Meyers R, Moosavi M, Oliver J, Till K, Williams C. The long-term athlete development model: physiological evidence and application. J Sports Sci. 2011;29(4):389-402. https://doi.org/10.1080/ 02640414.2010.536849.

53. Erčulj F, Blas M, Bračič M. Physical demands on young Elite European female basketball players with special reference to speed, agility, explosive strength, and take-off power. J Strength Cond Res. 2010;24(11):29708. https://doi.org/10.1519/JSC.0b013e3181e38107.

54. Myburgh G, Cumming S, Coelho-e-silva MJ, Cooke K, Malina RM. Maturity-associated variation in functional characteristics of elite youth tennis players. Pediatr Exer Sci. 2016;28:542-52. https://doi.org/10.1123/ pes.2016-0035.

55. Sherar LB, Cumming SP, Malina RM. Adolescent biological maturity and physical activity: biology meets behavior. Pediatr Exer Sci. 2010;22:33249. https://doi.org/10.1123/pes.22.3.332.

56. Sekine Y, Hoshikawa S, Hirose N. Longitudinal age-related morphological and physiological changes in adolescent male basketball players. J Sports Sci Med. 2019;18(4):751-7.

57. Armstrong N, Welsman JR, Williams CA, Kirby BJ. Longitudinal changes in young people's short-term power output. Med Sci Sports Exerc. 2000;32:1140-5. https://doi.org/10.1097/00005768-200006000-00017.

58. Geithner CA, Thomis MA, Vanden Eynde B, Maes HH, Loos RJ, Peeters M, Claessens AL, Vlietinck R, Malina RM, Beunen GP. Growth in peak aerobic power during adolescence. Med Sci Sports Exerc. 2004;36(9):1616-24. https://doi.org/10.1249/01.mss.0000139807.72229.41.

59. Bouchard C, Malina RM, Perusse L. Genetic of fitness and physical performance. Champaign, Human Kinetics. 1997.

60. Pearson DT, Naughton GA, Torode M. Predictability of physiological testing and the role of maturation in talent identification for adolescent team sports. J Sci Med Sport. 2006;9(4):277-87. https://doi.org/10.1016/j.jsams. 2006.05.020.

61. Barreiros A, Côté J, Fonseca AM. From early to adult sport success: analysing athletes' progression in national squads. Eur J Sport Sci. 2014;14(Suppl 1):S178-82. https://doi.org/10.1080/17461391.2012.671368.

62. Ford P, Collins D, Bailey R, MacNamara A, Pearce G, Toms M. Participant development in sport and physical activity: the impact of biological maturation. Eur J Sport Sci. 2012;12(6):515-26. https://doi.org/10.1080/ 17461391.2011 .577241

63. Geithner CA, Woynarowska B, Malina RM. The adolescent spurt and sexual maturation in girls active and not active in sport. Ann Hum Biol. 1998;25(5):415-23. https://doi.org/10.1080/03014469800006662.

64. Kaczmarek M. Adolescent growth and its relation to menarche, dental and somatic maturation. Anthropol Rev. 2002;65:27-42.

65. Granados A, Gebremariam A, Lee JM. Relationship between timing of peak height velocity and pubertal staging in boys and girls. $J$ Clin Res Pediatr Endocrinol. 2015;7(3):235-7. https://doi.org/10.4274/jcrpe.2007. 
66. Lee JM, Appugliese D, Kaciroti N, Corwyn RF, Bradley RH, Lumeng $J C$. Weight status in young girls and the onset of puberty. Pediatrics. 2007;119(3):e624-30. https://doi.org/10.1542/peds.2006-2188.

67. Malina RM, Kozieł SM. Validation of maturity offset in a longitudinal sample of Polish boys. J Sports Sci. 2014;32(5):424-37. https://doi.org/10. 1080/02640414.2013.828850.

68. Malina RM, Rogol AD, Cumming SP, Coelho e Silva MJ, Figueiredo AJ. Biological maturation of youth athletes: assessment and implications. Br J Sports Med. 2015;49(13):852-9. https://doi.org/10.1136/bjspo rts-2015-094623.

69. Müller L, Müller E, Hildebrandt C, Kapelari K, Raschner C. Die Erhebung des biologischen Entwicklungsstandes für die Talentselektion - welche Methode eignet sich? [The assessment of biological maturation for talent selection - which method can be used?]. Sportverletzung Sportschaden : Organ der Gesellschaft fur Orthopadisch-Traumatologische Sportmedizin. 2015;29(1):56-63. https://doi.org/10.1055/s-0034-1399043

70. Koopmann T, Faber I, Baker J, Schorer J. Assessing technical skills in talented youth athletes: a systematic review. Sports Med. 2020;50(9):1593611. https://doi.org/10.1007/s40279-020-01299-4.

\section{Publisher's Note}

Springer Nature remains neutral with regard to jurisdictional claims in published maps and institutional affiliations.

- fast, convenient online submission

- thorough peer review by experienced researchers in your field

- rapid publication on acceptance

- support for research data, including large and complex data types

- gold Open Access which fosters wider collaboration and increased citations

- maximum visibility for your research: over 100M website views per year

At BMC, research is always in progress.

Learn more biomedcentral.com/submissions 